\title{
Severe endobronchial obstruction in a girl with relapsing polychondritis: treatment with Nd YAG laser and endobronchial silicon stent
}

\author{
O. Sacco*, B. Fregonese*, M. Oddone**, A. Verna+, E. Tassara+, \\ C. Mereu*, G.A. Rossi*
}

Severe endobronchial obstruction in a girl with relapsing polychondritis: treatment with Nd YAG laser and endobronchial silicon stent. O. Sacco, B. Fregonese, M. Oddone, A. Verna, E. Tassara, C. Mereu, G.A. Rossi. (C) ERS Journals Ltd 1997.

ABSTRACT: Relapsing polychondritis (RP) is an uncommon disorder of unknown aetiology characterized by inflammation and destruction of the cartilaginous structures of many organs, including the tracheobronchial tree. When untreated, there is a high mortality rate, usually from respiratory obstructive complications.

An 8 year old white girl, with a previous diagnosis of RP, was referred to our department for evaluation of worsening dyspnoea. Bronchoscopy showed localized inflammatory and fibrotic alterations of the mucosa, leading to severe obstruction of the left mainstem bronchus at its origin. The condition was successfully treated by endoscopic neodymium yttrium aluminium garnet (Nd YAG) laser. Re-evaluation of the patient, 7 months later, demonstrated bronchial stenosis and malacia requiring mechanical dilatation and positioning of an endobronchial silicon stent, which was well-tolerated by the patient.

Eur Respir J 1997; 10: 494-496.
*Pulmonary Division and **Radiology Service, G. Gaslini Institute, Genoa, Italy. +Endoscopy Respiratory Center, Dept of Oncology, National Cancer Institute, University of Genoa, Genoa, Italy.

Correspondence: G.A. Rossi

Pulmonary Division

G. Gaslini Institute

Largo G. Gaslini 5

16147 Genoa

Italy

Keywords: Atelectasis, laser therapy, relapsing polychondritis, silicon stent

Received: March 191996

Accepted after revision September 201996
Relapsing polychondritis is an uncommon inflammatory disease of unknown cause affecting cartilages in many organs and systems $[1,2]$. This disorder is manifested by recurrent and, generally, progressive inflammation of the cartilaginous portion of the external ear, joints, cardiovascular system and respiratory tract [2, 3]. At the airway level, the extent of the disease may vary and all cartilage-containing structures can be affected [4]. Although onset of relapsing polychondritis may vary, the majority of cases appear between the ages of 40 and 60 yrs, with an equal sex distribution and no known familial predisposition [2-4].

The most widely-accepted hypothesis for the pathogenesis of polychondritis is that a primary or secondary immune reaction against mucopolysaccharide components of cartilage ground substance results in severe inflammatory changes leading to the destruction of cartilage $[4,5]$. Histologically, the characteristic abnormalities are: 1) focal or diffuse loss of basophilic staining, indicating depletion of proteoglycans from the cartilage matrix; 2) inflammatory infiltrates, consisting predominantly of mononuclear cells and plasma cells; and 3) destruction of the cartilage with loss of chondrocytes [2-5].

When untreated, this disorder is associated with a high mortality rate, usually from respiratory and cardiovascular complications, such as obstructive pneumonia, aortic valve disease and aortic aneurysm [4-7]. In addition to anti-inflammatory and immunosuppressive drugs, airway lesions may require a variety of interventions, including tracheostomy and bronchial resection [8].

\section{Case report}

An 8 year old Caucasian girl was referred to our department for evaluation of worsening dyspnoea. At another institution, a diagnosis of relapsing polychondritis had been made 18 months previously, on the basis of the presence of: 1) nasal chondritis, resulting in collapse of the nasal bridge with a saddle deformity; 2) clinical, roentgenographic and endoscopic demonstration of inflammatory alteration of cartilages of the proximal trachea; 3 ) histological abnormality of tracheal cartilage on forceps biopsy obtained during bronchoscopy, consistent with the diagnosis; and 4) mild leucocytosis, elevated sedimentation rate and low titre antinuclear antibody test positivity. No clinical signs of auricular chondritis were present. Because of the presence of respiratory symptoms and the fear of a possible life-threatening airway obstruction, treatment with prednisone $\left(1 \mathrm{mg} \cdot \mathrm{kg}^{-1}\right.$ daily), azathioprine ( $1.5 \mathrm{mg} \cdot \mathrm{kg}^{-1}$ daily), and cyclosporin (1.5 $\mathrm{mg} \cdot \mathrm{kg}^{-1}$ daily) was initiated at that time.

On admission, physical examination demonstrated decreased breath sound with inspiratory and expiratory rhonchi over the left hemithorax. Transcutaneous blood gas determination in room air showed a slight decrease of arterial oxygen tension $\left(\mathrm{Pa}, \mathrm{O}_{2} 12.4 \mathrm{kPa}(93 \mathrm{mmHg})\right)$ with normocapnia arterial carbon dioxide tension $\left(\mathrm{Pa}_{\mathrm{a}}, \mathrm{CO}_{2}\right)$ $5.2 \mathrm{kPa}(39 \mathrm{mmHg})$. Results of routine blood tests were within normal values, including white cell counts, electrophoresis of serum proteins and immunoglobulin ( $\mathrm{Ig}$ ) levels $\left(\mathrm{IgG}=1,210 \mathrm{mg} \cdot \mathrm{dL}^{-1} ; \operatorname{IgM}=147 \mathrm{mg} \cdot \mathrm{dL}^{-1} ; \operatorname{IgA}=\right.$ $194 \mathrm{mg} \cdot \mathrm{dL}^{-1}$ ). The antinuclear antibody (ANA) test was 
weakly positive, with a speckled pattern. The antimitochondrial (AMA) anti-smooth muscle (ASMA), antityreoglobulin (ATA) and antineutrophil cytoplasmic (ANCA) antibody assays were negative. Hyperinflation of the left hemithorax was seen on chest radiographs (fig. 1a). Computed tomography (CT) and magnetic resonance imaging (MRI) demonstrated a severe obstruction of the left mainstem bronchus (fig. 1b) associated with subglottic irregularity of the tracheal wall. A mild-to-moderate decrease of the forced vital capacity (FVC) and of pulmonary flows was associated with a maximal expiratory and inspiratory flow-volume loop consistent with a fixed obstruction of the central airways [9].

Fibreoptic bronchoscopy was performed and demonstrated: 1) subglottic irregularity of the tracheal wall, due to fibrotic scarring of the previously described lesions, not determining any airway obstruction; 2) mucosal inflammatory-fibrotic alterations, covered by fibrinoid material, localized at the origin of the left mainstem bronchus, inducing a severe obstruction of its lumen;

a)

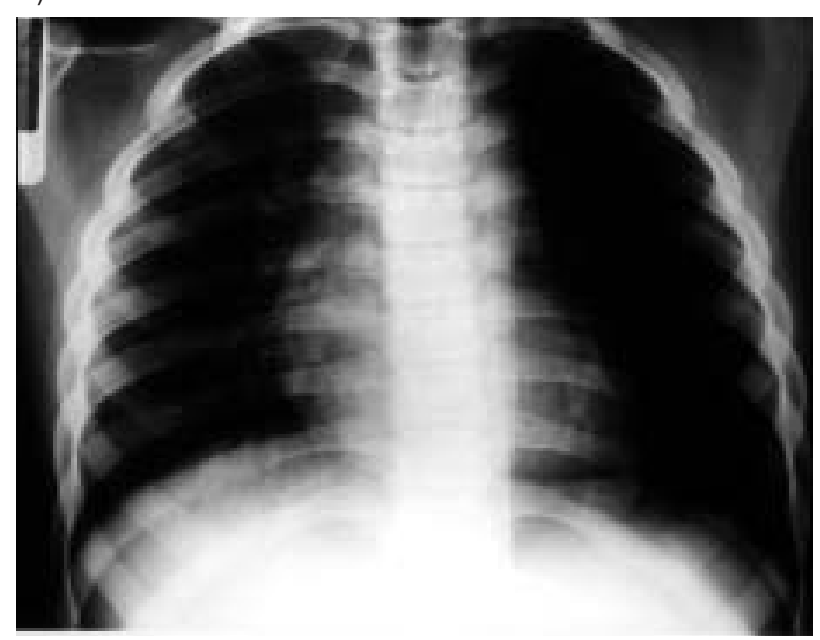

b)

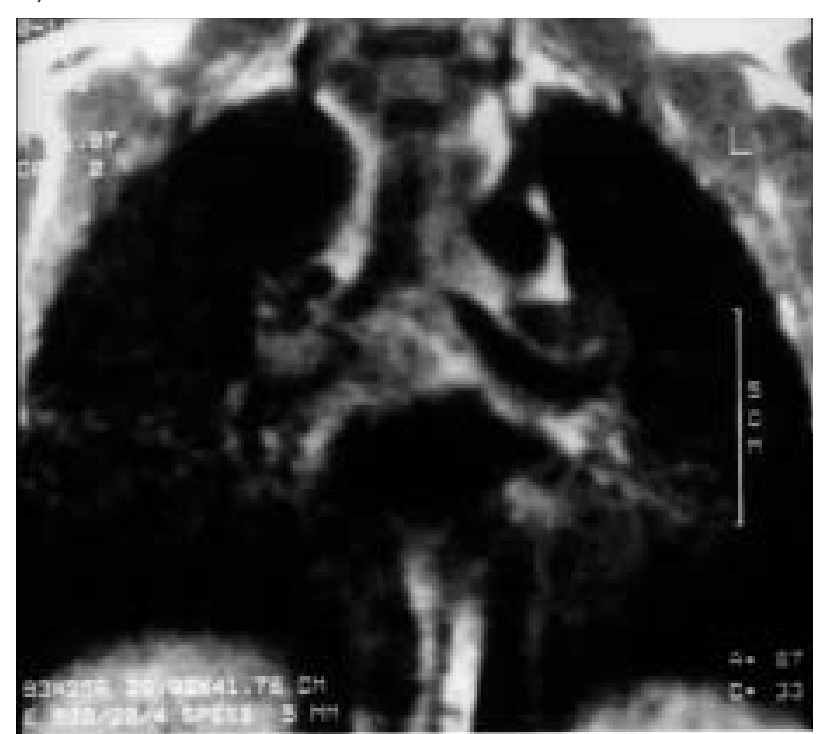

Fig. 1. - Evaluation of the patient with relapsing polychondritis on admission: a) Posteroanterior (PA) chest radiograph showing hyperinflation of the left lung. b) Coronal T1 weighted magnetic resonance image (MRI) demonstrating severe obstruction of the left mainstem bronchus. and 3) two deep inflammatory-necrotic ulcerations, seen at the levels of the tracheal carina and the origin of the upper right bronchus. Histological evaluation of bronchial biopsies demonstrated, together with fibrotic changes, an inflammatory reaction characterized by the presence of mononuclear cells and granulocytes, also infiltrating the small submucosal vessel walls.

Endobronchial treatment of the obstructing lesions was performed with neodymium yttrium aluminium garnet (Nd YAG) laser, under general anaesthesia, by rigid bronchoscopy, which resulted in complete canalization of the mainstem left bronchus in one session. In the following 10 days, four more fibreoptic bronchoscopies were performed to clean the fibrinoid material covering the laser-treated area and to keep the left mainstem bronchus patent.

Re-evaluation of the patient 1 month later demonstrated normal chest radiographs and pulmonary function test values (including inspiratory and expiratory flow-volume curves). However, fibreoptic bronchoscopy showed a slight reduction in diameter of the left mainstem bronchus at its proximal end, in the same portion that was treated with $\mathrm{Nd}$ YAG laser, due to malacia of the wall more than to relapsing of inflammatory-fibrotic lesions. Therefore, immunosuppressive therapy was reduced (prednisone $\left(0.50 \mathrm{mg} \cdot \mathrm{kg}^{-1}\right.$ daily), azathioprine $\left(0.75 \mathrm{mg} \cdot \mathrm{kg}^{-1}\right.$ daily), and cyclosporine (1.0 $\mathrm{mg} \cdot \mathrm{kg}^{-1}$ daily)) and the patient discharged.

Six months later, the patient was re-evaluated and physical examination, chest radiographs and pulmonary function tests suggested recurrence of the bronchial obstruction. Fibreoptic bronchoscopy revealed a concentric stenosis (50\% reduction of the diameter) of the left mainstem bronchus, due to fibrotic alteration and to more severe malacia of the bronchial wall related to destruction of the cartilages. Mechanical dilatation was performed through a rigid bronchoscope, followed by positioning of a silicon prosthesis Dumon stent, bronchial oblique, diameter $10 \mathrm{~mm}$, length $20 \mathrm{~mm}$; Axion-Endoxane, Bologna, Italy) in the left mainstem bronchus. Ten days later, the patient was discharged and control fibreoptic bronchoscopy, 2, 8 and 12 months later, confirmed the patency of the left bronchus, with the stent being in the right position. Sequential evaluation (2,8 and 12 months after positioning of the silicon prosthesis) of the two inflammatory ulcerations, seen at the levels of the tracheal carina and the origin of the upper right bronchus, demonstrated partial healing of the first one, while the second appeared unchanged.

\section{Discussion}

Relapsing polychondritis is a connective tissue disorder characterized by widespread destructive inflammatory lesions of cartilaginous structures throughout the body [1-4]. Although onset may vary from birth to the ninth decade, only a few cases have been reported in childhood [2-4, 9-12]. The aetiology is unknown, but mounting evidence suggests that this disorder is characterized by a selected perturbation of connective tissue structures with mucopolysaccharide depletion $[4,5]$. This can be the result of: 1) excessive release of proteolytic enzymes by chondrocytes or leucocytes; 2) downregulation of proteoglycans and collagen synthesis; 3 ) 
primary or secondary autoimmune reactions against cartilage intercellular matrix components [13-16].

The clinical manifestations of relapsing polychondritis may vary considerably; however, over half of the patients reported have been found to have manifestations in the respiratory tract $[4,9,17]$. Involvement of the airways can lead to obstruction, as a consequence of inflammatory swelling, during the active stages of the disease, or dissolution of the tracheal or bronchial cartilage and scarring, during the latest stages of the disease [9]. Tracheal and bronchial obstruction is often complicated by pulmonary infections, due to impaired clearance of secretions, which are responsible for approximately $50 \%$ of the deaths $[1,4,9]$.

As for other connective tissue diseases, anti-inflammatory and immunosuppressive agents are considered the drugs of choice in patients with relapsing polychondritis $[11,18,19]$ and, although there is no evidence that these drugs alter the natural course of the disease, they may be effective in suppressing the acute manifestations and, possibly, in reducing the frequency and the severity of recurrences. In our patient, a combination of prednisone, azathioprine, and cyclosporin was only partially effective against the inflammatory component of the bronchial lesions observed. Immunosuppressive treatment can, however, decrease the defence mechanisms, further increasing the risk of obstructive pneumonia. Indeed, in the patient described here, multiple cultures of airway secretions obtained during fibreoptic bronchoscopy revealed chronic airway colonization by Pseudomonas aeruginosa and Staphylococcus aureus.

In addition to medical treatment, if the obstruction is localized to glottic or subglottic regions, tracheostomy may be necessary to save the subject's life $[8,9]$, while localized refractory stenosis or collapse of the tracheobronchial tree may be managed with segmental resection. More extensive involvement may require prolonged endotracheal intubation, external tracheal splinting, or the use of a silastic tube prosthesis or silicon or metal stent [8]. In this patient, the site of the obstructive bronchial lesion (proximal end of the left mainstem bronchus) made any surgical approach impossible. Our experience proves that bronchial recanalization with neodymium yttrium aluminium garnet laser therapy followed by the use of a silicon endoprosthesis (if reactivation of the underlying disorder is resulting in recurrence of bronchial obstruction) may be considered an effective therapeutic approach to endobronchial lesions in patients with relapsing polychondritis.

\section{References}

1. Pearson CM, Klin HM, Newcomer VD. Relapsing polychondritis. N Engl J Med 1960; 263; 51-58.
2. Kaye RL, Sones DA. Relapsing polychondritis: clinical and pathological features in fourteen cases. Ann Intern Med 1964; 60: 653-664.

3. Dolan DL, Lemmon GB Jr, Teitelbaum SL. Relapsing polychondritis: analytical literature review and studies on the pathogenesis. Am J Med 1966; 41: 285-299.

4. McAdam LP, O'Hanlan A, Bluestone R, Pearson CM. Relapsing polychondritis: prospective study of 23 patients and a review of the literature. Medicine 1976; 55: 193-215.

5. Herman JH. Polychondritis. In: Kelly WN, Harris ED, Ruddy S, Sledge CB, eds. Textbook of Rheumatology. Philadelphia, Saunders, 1981; 2: 1500-1508.

6. Kresina TF, Yoo JU, Goldberg VM. Evidence that a humoral immune response to autologous cartilage proteoglycan can participate in the induction of cartilage pathology. Arthritis Rheum 1988; 31: 248-253.

7. Michet CJ, McKenna CH, Luthra HS, O'Fallon WM. Relapsing polychondritis. Survival and predictive role of early disease manifestations. Ann Intern Med 1986; 104: 74-78.

8. Burgess FW, Whiitlock W, Davis MJ. Anaesthetic implication of relapsing polychondritis: a case report. Anaesthesiology 1990; 73: 570-575.

9. Mohsenfar Z, Tashkin DP, Carson SA, Bellamy PE. Pulmonary functions in patients with relapsing polychondritis. Chest 1982; 81: 711-717.

10. Oddone $\mathrm{M}$, Tomà $\mathrm{P}$, Taccone $\mathrm{A}$, Hanau $\mathrm{G}$, Delongu $\mathrm{A}$, Gemme G. Relapsing polychondritis in childhood: a rare observation studied by CT and MRI. Paediatr Radiol 1992; 22: 537-538.

11. Prasad S, Grundfast KW, Linpick R. Airway obstruction in an adolescent with relapsing polychondritis. Otolaryngol Head Neck Surg 1990; 103: 113-116.

12. Trepel RJ, Lipnick RN, D'Angelo L. Relapsing polychondritis in an adolescent. J Adolesc Health Care 1989; 10: 557-560.

13. Herman JH, Dennis MV. Immunopathologic studies in relapsing polychondritis. J Clin Invest 1973; 52: 549-556.

14. Foidart JM, Abe S, Martin GR. Antibodies to type II collagen in relapsing polychondritis. N Engl J Med 1978; 299; 1203-1207.

15. Diebold L, Rauh G, Jager K, Lohrs U. Bone marrow pathology in relapsing polychondritis: high frequency of myelodysplastic syndromes. Br J Haematol 1995; 89: 820-830.

16. Saxne T, Heinegard D. Serum concentrations of two cartilage matrix proteins reflecting different aspects of cartilage turnover in relapsing polychondritis. Arthritis Rheum 1995; 38: 294-296.

17. Swenson KLG, Homdahl R, Klareskgog L. Cyclosporin A treatment in a case of relapsing polychondritis. Scand J Rheumatol 1984; 13: 329-333.

18. Van der Lubbe PA, Miltenburg AM, Breedveld FC. Anti CD4 monoclonal antibody for relapsing polychondritis. Lancet 1991; 337: 1349.

19. Davis SD, Berkmen YM, King T. Peripheral bronchial involvement in relapsing polychondritis: demonstration by thin-section CT. AJR 1989; 153: 953-958. 